\title{
A Cross-Sectional Research on Factors Associated with Depression Among Transgender Women in Bangkok, Thailand
}

\author{
Pankaew Tantirattanakulchai, Nuchanad Hounnaklang, Naowarat Kanchanakhan
}

\begin{abstract}
Depression is becoming a major mental health problem globally. Thailand is known as the accepting society for transgender but the available study on transgender women dealing with depression is scarce. This study aims to describe the prevalence of depression among Thai transgender women in Bangkok and to explore the associated factors. A cross-sectional study was conducted among 108 Thai transgender women in Bangkok, Thailand from January 2019 to April 2019. Data were collected through self-administered. Depression was assessed by using The Center for Epidemiological Studies-Depression Scale (CES-D). Multivariate regression analysis was conducted to explore the associated factors of depression. The prevalence of depression among transgender women in this study was $54.6 \%$. Factors associated with depression in the crude analysis were: sex reassignment surgery $(O R=2.45,95 \% C I=0.96-6.24)$, illness history $(O R=1.79,95 \% C I=0.72-4.50)$. In multivariate logistic regression analysis, depression was significantly associated with drinking alcohol $>1$ time/month in the past 12months (adjusted $O R=0.33,95 \% C I=0.12-0.91)$. Transgender tend to experience higher rates of mental health issues than the general population. This study suggested that alcohol drinking was only significantly associated with depression in Thai transgender women. For further study, we need to find other associations with depression in transgender community.
\end{abstract}

Keywords - transgender women, depression, alcohol

\section{INTRODUCTION}

Transgender is an umbrella term used to describe a group of people in society that do not identify nor feeling comfortable in expressing their gender of birth. This group has a diverse representation across all segments of society, countries and worldwide [1]. In Thailand, they have developed into specific cultural groups. They are referred to by many terms. Some of these terms are used to describe different types of gender. Today, Kathoey or a second type of woman (sao praphet song) is commonly used by the Thai society to identify them [2].

Depression has been determined to be a major cause of poor health and disability globally, and today is one of the major contributors to the worldwide burden of disease. By 2020, The World Health Organization (WHO) predicted that depression will rank second in global burdens of disease [3]. At a global level, in 2015 the total amount of all ages, suffering from depression, was estimated to exceed 322

\footnotetext{
Revised Manuscript Received on July 18, 2019.

Pankaew Tantirattanakulchai, College of Public Health Sciences, Chulalongkorn University, Bangkok 10330, Thailand. (6178830253@student.chula.ac.th)

Nuchanad Hounnaklang, College of Public Health Sciences, Chulalongkorn University, Bangkok 10330, Thailand. (nhounnaklang@yahoo.com)

Naowarat Kanchanakhan, College of Public Health Sciences, Chulalongkorn University, Bangkok 10330, Thailand
} (naowarat.K@chula.ac.th) drinking, illness history, sex reassignment surgery

million people, equivalent to 4.4 percent of world's population. This total number increased by $18.4 \%$ between 2005 and 2015 [4]. In addition, WHO global health estimates in 2015 reported that depression is more common among female $5.1 \%$ than male $3.6 \%$ [4]. Among general population, the prevalence of depression is higher among women between women and men was reported to be in the ratio 2:1 [5]. Among lesbian, gay, bisexual, and transgender, the mental health disorder is still one of the greatest areas of clinical concern [6]. People with gender identity disorder is normally connected with severe stress, depression and social isolation [7]. Transgender women are thought to be at the highest risk in the LGBT communities for mental health problems. One of the major mental health problems among transgender population is depression. It is important to stress that depression is seldom caused by identifying as a transgender [8]. The high lifetime prevalence rate of depression among male to female transgender is ranging from $48 \%$ to $62 \%$. A study has showed that transgender individuals experience higher levels of depression than the general population [9].

People who have depression may also have symptoms that affect feeling, thinking, and the ability to handle daily activities, such as sleeping, eating, or working [10]. Furthermore, Severe depression can not only reduce the quality of life of individuals but also associated with other health problems [11]. According to the recent study, there was higher chance to get diseases like myocardial infarction, stroke, and peripheral artery disease if people have depression which can be considered as an independent variable for having chronic diseases [12]. Depression can also be placed as a dependent variable where independent variables were having chronic diseases, disabilities [13]. Sometime, depression is referred to as "the common cold of mental illness". While the common cold infrequently kills anyone, the clinical depression on the other hand often does. Given a long duration of the hopelessness from depression, it is not surprising that some depressed people ultimately attempt suicide. In the most severe form, depression can lead to suicide [14]. Depression is a major contributor to suicide deaths, and it is estimated that close to 800,000 people die from suicide annually. In 2015, suicides accounted for $1.5 \%$ of global total deaths. that bringing suicide into the top twenty leading causes of death [4].

The most vulnerable group, affected by depression or suicide are these who experience discrimination, including: LGBT, 


\section{A CROSS-SECTIONAL RESEARCH ON FACTORS ASSOCIATED WITH DEPRESSION AMONG TRANSGENDER WOMEN IN BANGKOK, THAILAND}

refugees and migrants[15]. One of the major causes of depression and suicide among the transgender population is the lack of social support. Many transgender people claim that they do not receive adequate social support, with their families and peer groups failing to meet their needs. The problem is exacerbated in public areas where they suffer inconvenience and feel insecure or unsafe [16]. Research carried out in China suggests that it is the Confucian culture which leads to transgender people becoming a hidden part of society. This is because Confucianism holds that the laws of nature must be followed, and transgender people are different and do not fit these natural laws. Hence, they are shunned and treated differently by society. When family members also fail to support these transgender people, depression is often the result [17]. Transgender women greatest fear that coming out and exposing that they are transgender may cause rejection by family and friends. This fear cause many to keep this feeling to themselves and suppressing their true gender identity and feelings. This in turn increase the risk of depression. This finding is consistent with previous researches that the fear of exposing their gender identity as transgender women was extremely stressful and was in direct correlation with denial by family and peer [18].

There are very few researches dealing with depression of the Thai transgender women population. The study on transgender women is scarce, and no national-level health surveillance survey presently collects data that can be used to reliably identify the depression these populations. To our knowledge, no empirical investigation has examined similar rates of depression among Thai transgender women populations. This study's objective aimed at evaluating the prevalence of depression and also determine the association between social support and depression among transgender women who living in Bangkok, Thailand. The findings in this research are expected to be of benefit in guiding both providers of health care and health policy maker to offer improved services which will specifically deliver greater support to the transgender community, resulting in enhanced mental health outcomes especially in the case of Thai transgender women.

\section{METHOD}

\section{Participants and procedure}

A cross-sectional study was conducted in Bangkok, Thailand from March 2019 to April 2019 using snowball sampling technique. To be eligible for this study, participants were at least 18 years old, resided in Bangkok for the most recent 6 months, self-identified as male to female transgender, changed physical appearance and live as a woman, can communicate in Thai, read and write well, likely to participated, whatever doing or not doing sex reassignment surgery were included. Those who were have a thought or a plan about being back to be a man or gay were excluded. Data were collected through self-administered after briefing, screening eligibility for inclusion and exclusion criteria and obtaining verbal informed consent. A total of 108 Thai transgender women suitable with the criteria were enrolled in this study.

\section{Ethics statement}

This study protocol and informed consent form received ethics approval from The Research Ethics Review
Committee for Research Involving Human Research Participants, Health Sciences Group, Chulalongkorn University. The transgender women who expressed interest in this study were asked for verbal informed consent. Verbal informed consent followed detailed description of the purpose and procedures of this study, benefits, participant's confidentiality and the rights of participants. Each set of questionnaires were taken time for answer about 20 minutes. All of participants were offered a gift to compensate them for their time and effort.

\section{Measurements}

\section{Sociodemographic characteristics}

Sociodemographic characteristics included age, educational level, monthly income, occupation, living status, sex reassignment surgery, sexual-partnership and health status. educational level was categorized as $\leq$ High school/ Vocational certificate, Bachelor degree, > Bachelor degree. Monthly income (Baht) was divided in to groups of $\leq$ 20,000', '20,000-30,000'and > 30,000. Occupation was categorized as student, unemployed, government officer, company employee, business owner and freelancer. Living status was categorized as living alone, with family, with partner and with friend. Health status was assessed by: sex reassignment surgery (yes/no), sexual-partnership (yes/no), cross-sex hormone use (yes/no), illness history (yes/no), Substance use (yes/no), smoking in the past 12 months was categorized as never, ever and ex-smoker. Alcohol drinking in the past 12 months was categorized as no, < 1time/month 1-3 day/month, 1-2 day/week, 3-4 day/week, 5-7 day/week.

\section{Assessment of depression}

The Center for Epidemiological Studies-Depression Scale (CES-D) [19] was used to access depression in the present study. This CES-D scale is composed of 20 items. The total score is between $0-60$. A validated cut-off score of more than or equal to 16 points was applied. Transgender women with depression have a total score 16 or higher $(\geq 16-60)$ and without depression, with a score of less than 16 points (0-15). The questionnaire is used in four Likert's scale. The scoring of all 16 negative questions is as follows: (0) "rarely or none of the time", (1) "some or a little of the time", (2) "occasionally or a moderate amount of the time" and (3) "most or all of the time" [20]. The scoring of all 4 positive questions were reversed.

\section{Statistical analysis}

Descriptive analyses were conducted to demonstrate the characteristics of transgender women with and without depression, and to analyze the prevalence of depression. Logistic regression analysis was performed to identify characteristics associated with depression. All variables with a $P$-value of $<0.2$ in a bivariate logistic regression analysis were considered for inclusion in a multivariable logistic regression model. Then multivariate regression analysis was conducted to investigate the associations which were statistically significant with $P$-value $<0.05$ and adjusted odds ratio (AOR) with $95 \%$ confidence interval (CI) was 
calculated. Statistical analysis was performed using the Statistical Packaged for Social Science version 22.0.

\section{RESULTS}

Participants baseline characteristics were shown in Table1. A total of 108 transgender women agreed to participate in this study. The age of transgender women ranged from 18 to 53 years old with $34(30.6 \%)$ of participants between 25 and 30 years old. Fifty-nine (54.6\%) of participants suffered from depression, 52 (48.1\%) had educational level in Bachelor degree, 46 (42.6\%) had monthly income $\leq 20,000$ baht, $35(32.4 \%)$ were company employee, $54(50.0 \%)$ lived with their family. Surprisingly, $84(77.8 \%)$ without sex reassignment surgery but 65 (60.2\%) used cross-sex hormone. Sixty-four (59.3\%) had sexual partnership, $82(75.9 \%)$ had no illness history, 56 $(51.9 \%)$ smoked in the past 12 months, $46(42.6 \%)$ and 100 (92.6\%) without substance use.

In the crude analysis, characteristics associated with depression were: sex reassignment surgery [odds ratio (OR) 2.45, 95\% confidence interval (CI) 0.96-6.24], illness history (OR 1.79, 95\%CI 0.72-4.50), drinking alcohol >1 time/month in the past 12 months (OR 0.29 , 95\%CI $0.11-$ 0.76) (Tale2). After adjusting for covariates, no association was found in sex reassignment surgery $(P=0.08)$, illness history $(P=0.30)$. The multivariate logistic regression analysis showed that depression was significantly associated with more drinking $>1$ time/month in the past 12 months (OR 0.33, 95\%CI 0.12-0.91; $\mathrm{P}=0.03$ ) (Table3).

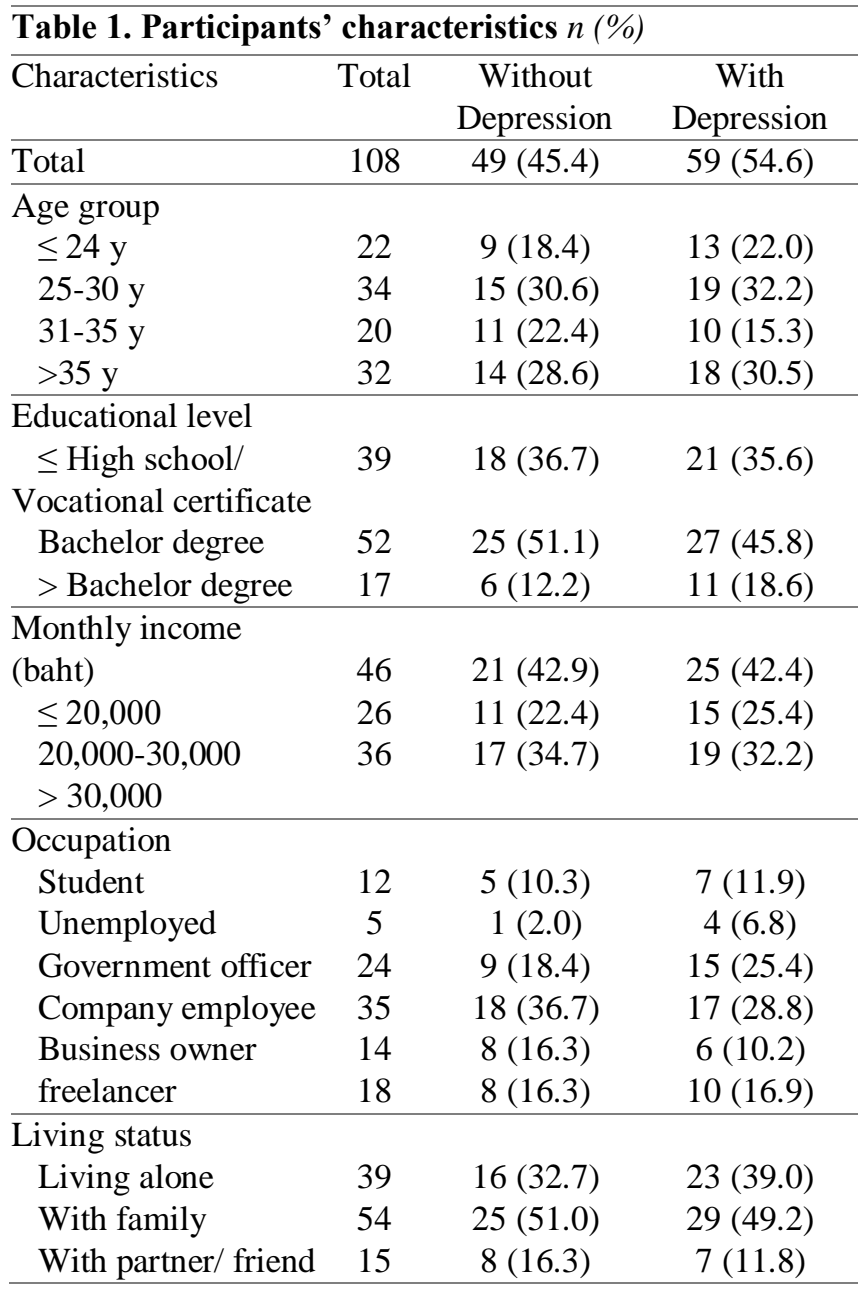

\begin{tabular}{|c|c|c|c|}
\hline \multicolumn{4}{|l|}{ Sex reassignment } \\
\hline No & 24 & $15(30.6)$ & $9(15.3)$ \\
\hline \multicolumn{4}{|l|}{ Yes } \\
\hline \multicolumn{4}{|l|}{ Sexual partnership } \\
\hline No & 44 & $19(38.8)$ & $25(42.4)$ \\
\hline Yes & 64 & $30(61.2)$ & $34(57.6)$ \\
\hline \multicolumn{4}{|l|}{ Cross-sex hormone } \\
\hline use & 43 & $18(36.7)$ & $25(42.4)$ \\
\hline No & 65 & $31(63.3)$ & $34(57.6)$ \\
\hline \multicolumn{4}{|l|}{ Yes } \\
\hline \multicolumn{4}{|l|}{ Illness history } \\
\hline No & 82 & $40(81.6)$ & $42(71.2)$ \\
\hline Yes & 26 & $9(18.4)$ & $17(28.8)$ \\
\hline \multicolumn{4}{|c|}{$\begin{array}{l}\text { Smoking } \\
\text { in the past } 12 \text { months }\end{array}$} \\
\hline Never & 52 & $25(51.0)$ & $27(45.8)$ \\
\hline Ever & 56 & $24(49.0)$ & $32(54.2)$ \\
\hline \multicolumn{4}{|c|}{$\begin{array}{l}\text { Alcohol drinking } \\
\text { in the past } 12 \text { months }\end{array}$} \\
\hline No & 31 & $9(18.4)$ & $22(37.3)$ \\
\hline$<1$ time/month & 31 & $13(26.5)$ & $18(30.5)$ \\
\hline$>1$ time/month & 46 & $27(55.1)$ & $19(32.2)$ \\
\hline \multicolumn{4}{|l|}{ Substance use } \\
\hline No & 100 & $46(93.9)$ & $54(91.5)$ \\
\hline Yes & 8 & $3(6.1)$ & $5(8.5)$ \\
\hline
\end{tabular}

Table 2. Participants' characteristics associated with depression using univariate logistic regression

\begin{tabular}{|c|c|c|}
\hline Characteristics & $\begin{array}{c}\text { Unadjusted OR } \\
(95 \% \mathrm{CI})\end{array}$ & $P$ \\
\hline \multicolumn{3}{|l|}{ Age group } \\
\hline$\leq 24 \mathrm{y}$ & Ref. & \\
\hline $25-30 y$ & $0.87(0.30-2.60)$ & 0.81 \\
\hline $31-35 y$ & $0.56(0.17-1.93)$ & 0.36 \\
\hline$>35 y$ & $0.89(0.30-2.67)$ & 0.83 \\
\hline \multicolumn{3}{|l|}{ Educational level } \\
\hline$\leq$ High school/ & $0.3(0.19-2.06)$ & 0.45 \\
\hline \multicolumn{3}{|l|}{ Vocational certificate } \\
\hline Bachelor degree & $0.59(0.19-1.83)$ & 0.36 \\
\hline$>$ Bachelor degree & Ref. & \\
\hline \multicolumn{3}{|l|}{ Monthly income } \\
\hline$\leq 20,000$ baht & $1.06(0.44-2.55)$ & 0.89 \\
\hline $20,000-30,000$ baht & $1.2(0.44-3.37)$ & 0.70 \\
\hline$>30,000$ baht & Ref. & \\
\hline \multicolumn{3}{|l|}{ Occupation } \\
\hline Student & Ref. & \\
\hline Unemployed & $2.86(0.24-33.90)$ & 0.40 \\
\hline Government officer & $1.19(0.28-4.90)$ & 0.80 \\
\hline Company employee & $0.67(0.18-2.54)$ & 0.56 \\
\hline Business owner & $0.54(0.11-2.55)$ & 0.43 \\
\hline freelancer & $0.89(0.20-3.91)$ & 0.88 \\
\hline \multicolumn{3}{|l|}{ Living status } \\
\hline Living alone & $1.24(0.54-2.85)$ & 0.61 \\
\hline With family & Ref. & \\
\hline With partner/ friend & $0.75(0.24-2.37)$ & 0.63 \\
\hline $\begin{array}{l}\text { Published By: } \\
\text { Blue Eyes Intel } \\
\text { \& Sciences Pub }\end{array}$ & & \\
\hline
\end{tabular}




\section{A CROSS-SECTIONAL RESEARCH ON FACTORS ASSOCIATED WITH DEPRESSION AMONG TRANSGENDER WOMEN IN BANGKOK, THAILAND}

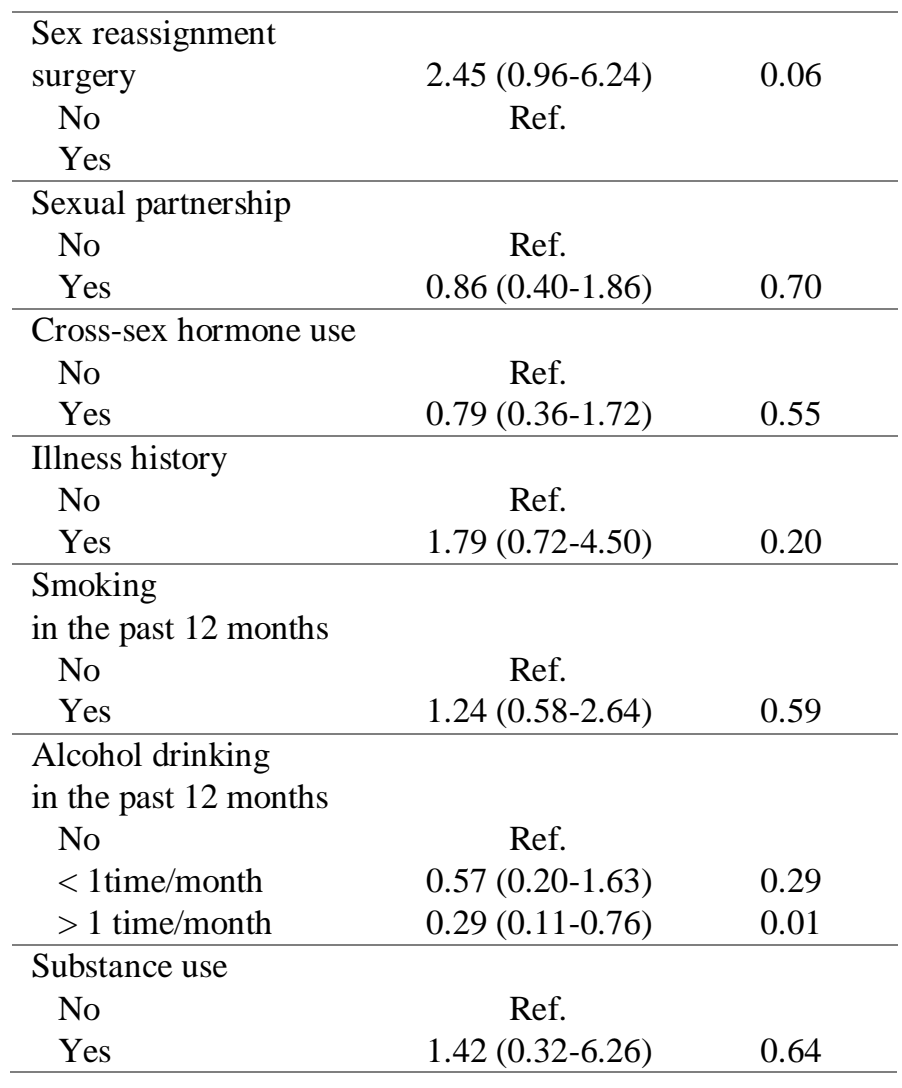

\section{DISCUSSION}

In this study, a total of 62.7 percent of transgender women who drink alcohol were found to be significantly associated with having depression. This result is consistent with a previous study by Bazargan-Hejazi et al. (2008) that showed that drinking alcohol within the last 12 months was significantly associated with higher rates of depression. Another supportive factor of the research, which was determined by using the bioinformatics method, is that alcohol consumption can result in lower levels of production of methylenetetrahydrofolate-reductase, which can cause a risk of clinical depression, or major depressive disorder. In fact, a large amount of previous research that has been conducted to investigate individuals who are heavy drinkers and/or meet the criteria for diagnosis of alcohol abuse or alcoholism found that they suffer from higher levels of depression; therefore, these findings are neither unexpected nor considered unusual [21, 22]. It is suggested by the literature that the likelihood of developing major depression increases in proportion to the higher amount of alcohol that a person consumes[23]. The findings from a previous study of a large sample population of 38,390 people in Norway indicated that there is a higher risk of anxiety and depression for both those who abstain from alcohol as well as for people who are excessive drinkers [24].

In our sudy, it was also found that there is no significant association between depression and sex reassignment surgery or illness history after adjusting for covariates. In contrast, most studies, including previous studies from the UK, showed that chronic illness has a significant negative impact on mental health or depression. However, there were differences in methodology, including the design of the study, the operational definition of illness history, the sampling method and also the sample size, between those studies and this current study. Another contrary result is that Dr. Hess and colleagues surveyed 156 people who had all had sex reassignment surgery, and the results indicated that 71 percent of 156 transgender women had a significant association with well-being in mental health after sex reassignment surgery. These results are the opposite of each other because there was a small sample size in our study, which is one of the limitations. In this study, sexual partnership was not significantly associated with depression, but in the findings of a Chinese transgender cross-sectional study, sexual partnership was not only found to be significant but was also shown to play a major role in having depression.

This was similar to a previous study in which there was no significant association between the number of sex partners and later anxiety and depression [25].

Table 3 Multivariate logistic regression analysis of association of depression with SRS, illness history and alcohol drinking in the past 12 months among transgender women

\begin{tabular}{|c|c|c|c|c|}
\hline & Unadjusted OR (95\%CI) & $P$ & ${ }^{\mathrm{a}}$ Adjusted OR (95\%CI) & $P$ \\
\hline \multicolumn{5}{|c|}{ Sex reassignment surgery } \\
\hline No & $2.45(0.96-6.24)$ & 0.06 & $2.35(0.89-6.20)$ & 0.08 \\
\hline Yes & Ref. & & Ref. & \\
\hline \multicolumn{5}{|l|}{ Illness history } \\
\hline No & Ref. & & Ref. & \\
\hline Yes & $1.79(0.72-4.50)$ & 0.20 & $1.67(0.62-4.46)$ & 0.30 \\
\hline \multicolumn{5}{|c|}{ Alcohol drinking in the past 12 months } \\
\hline No & Ref. & & Ref. & \\
\hline$<1$ time/month & $0.57(0.20-1.63)$ & 0.29 & $0.62(0.21-1.85)$ & 0.40 \\
\hline$>1$ time/month & $0.29(0.11-0.76)$ & 0.01 & $0.33(0.12-0.91)$ & $0.03^{*}$ \\
\hline
\end{tabular}

CI: Confidence interval, OR: SRS: Sex reassignment surgery

${ }^{*} P$ value significant at a level $<0.05$

Living status was not associated with or important to having depression in this study, while the factor of 'Living alone' (compared to living with a family member) was associated with elevated levels of depression. In our study, there was no significant association with hormone use and depression. However,

another study in France showed that hormone use and sex reassignment surgery can relieve depression. 
Furthermore, there was another study that indicated that hormone use has a positive effect on depression [26] [26]. There are several limitations to this study, the main one of which is that a cross-sectional study was chosen as the research design, and as a result, conclusions regarding the causality of the associations between transgender women and depression cannot be derived. In addition, this present study focused only on depression among transgender women, a topic on which few previous studies have been conducted in Thailand, and in addition, the target population was focused solely on transgender women who are living in Bangkok, Thailand. Moreover, the technique of snowball sampling was used for the selection of the transgender women included in this research, which can reduce the ability to generalize the results of this study and transfer them to other populations.

\section{CONCLUSION}

In conclusion, transgender tend to experience higher rates of mental health issues than the general population. This study suggested that alcohol drinking only was significantly associated with depression in Thai transgender women. Transgender people who are diagnosed with gender identity disorder wish to be the opposite gender, and have shown that they have problems in their daily functioning because of this gender problem. Therefore, we need further study to find many other associations with depression in transgender community.

\section{REFERENCES}

1. Sari L Reisnerr, T.P., JoAnne Keatley,Mauro Cabral,Tampose Mothopeng,Emilia Dunham,Claire E Holland,Ryan Max,Stefan D Baral, Global health burden and needs of transgender populations: a review. Lancet, 2016. 338(10042): p. 412-436.

2. Winter, S., Thai Transgenders in Focus: Their Beliefs About Attitudes Towards and Origins of Transgender. International Journal of Transgenderism, 2006. 9(2): p. 47-62.

3. World Health Organization, The world halth report 2001: Mental Health : now understanding,now hope. 2001.

4. World Health Organization, depression and other common mental disorders. WHO, 2017.

5. Puri, B., Hall A., Ho R, Psychosexual medicine. Handbook of Revision Notes in Psychiatry, Third Edition, 2014: p. 384.

6. Cochran SD, M.V., Sullivan JG, Prevalence of mental disorders, psychological distress, and mental health services use among lesbian, gay, and bisexual adults in the United States. Journal of Consulting and Clinical Psychology., 2003. 71(1): p. 53-61.

7. Wallien MS, S.H., Cohen-Kettenis PT., Psychiatric coorbidity among children with gender identity disorder. Journal of the American Academy of Child \& Adolescent Psychiatry, 2007. 46(1): p. 1307-14.

8. Bockting WO, M.M., Swinburne Romine RE, Hamilton A, Coleman E, Stigma, Mental Health, and Resilience in an Online Sample of the US
Transgender Population. American Journal of Public Health, 2013. 103(5): p. 943-951.

9. Budge, S.L., Adelson, J. L., \& Howard, K. A. S, Anxiety and depression in transgender individuals: The roles of transition status, loss, social support, and coping. Journal of Consulting and Clinical Psychology, 2013. 81(3): p. 545-557.

10. NIMH, Depression. Posted on the web at: https://www.nimh.nih.gov/health/topics/depression/i ndex.shtml, 2018.

11. M.Isabella Bisschop, D.M.W.K., Dorly J.H Deeg, Aartjan T.F Beekman, Willem van Tilburg, The longitudinal relation between chronic diseases and depression in older persons in the community: the Longitudinal Aging Study Amsterdam. Journal of Clinical Epidemiology, 2004. 57(2): p. 187-194.

12. Daskalopoulou M, G.J., Walters K, Osborn DP, Batty GD, Stogiannis D, et al., Depression as a risk factor for the initial presentation of twelve cardiac, cerebrovascular, and peripheral arterial diseases: Data Linkage Study of 1.9 Million Women and Men. . PLoS One, 2016. 11(4).

13. Katon W, L.E., Kroenke $\mathrm{K}$, The association of depression and anxiety with medical symptom burden in patients with chronic medical illness. Gen Hosp Psychiatry, 2007. 29(2): p. 147-155.

14. Carol Choo, J.D., Insu Song, Roger Ho, Cluster analysis reveals risk factors for repeated suicide attempts in a multi-ethnic Asian population. Asian Journal of Psychiatry, 2014. 8: p. 38-42.

15. World Health Organization, suicide. 2018.

16. Factor RJ, R.E., A study of transgender adults and their non-transgender siblings on demographic characteristics, social support, and experiences of violence. Journal of LGBT Health Research, 2007. 3(3): p. 11-30.

17. Yang X, W.L., Gu Y, Song W, Hao C, Zhou J, Zhang Q, Zhao Q., A cross-sectional study of associations between casual partner, friend discrimination, social support and anxiety symptoms among Chinese transgender women. Journal of Affective Disorders 2016. 203: p. 22-29.

18. Sarah M. Peitzmeier, F.Y., Rob Stephenson, Andrea L. Wirtz,Altanchimeg Delegchoimbol, Myagmardorj Dorjgotov, Stefan Baral, Sexual Violence against Men Who Have Sex with Men and Transgender Women in Mongolia: A Mixed-Methods Study of Scope and Consequences. PLoS ONE 2015. 10(10).

19. Radloff, L.S., The CES-D Scale: A Self-Report Depression Scale for Research in the General Population. Applied Psyhological measureent, 1997. 1(3): p. 385-401.

20. Mulrow CD, W.J.J., Gerety MB, Ramirez G, Montiel OM, Kerber C., Case-finding instruments for depression in primary care settings. Ann Intern Med, 1995. 122(12): p. 913-21. 


\section{A CROSS-SECTIONAL RESEARCH ON FACTORS ASSOCIATED WITH DEPRESSION AMONG TRANSGENDER WOMEN IN BANGKOK, THAILAND}

21. C, B.-B., The psychological benefits of moderate alcohol consumption: a review of the literature. Drug Alcohol Depend, 1985. 15: p. 305-322.

22. Peele S, B.A., Exploring the psychological benefits associated with moderate alcohol use: a necessary corrective to assessments of drinking outcomes? Drug Alcohol Depend, 2000. 60: p. 221-247.

23. Boden JM, F.D., Alcohol and depression. Addiction, 2011. 106(5): p. 906-914.

24. Christoffer Skogen J, H.S., Henderson M, et al. A, Anxiety and depression among abstainers and lowlevel alcohol consumers.The Nord-Trøndelag Health Study. Addiction, 2009. 104(9): p. 1519 - 1529.

25. Sandhya Ramrakha, C.P., Melanie L. Bell, Nigel Dickson, et al, The Relationship Between Multiple Sex Partners and Anxiety, Depression, and Substance Dependence Disorders: A Cohort Study Arch Sex Behav, 2013. 42(5): p. 863-872.

26. Gómez-Gil E, Z.-E.L., Esteva I, Guillamon A, Godás T, Cruz Almaraz M, Halperin I, Salamero M., Hormone-treated transsexuals report less social distress, anxiety and depression. Psychoneuroendocrinology, 2012. 37(5): p. 662-70. 